\title{
Fixed and variable components of evapotranspiration in a Mediterranean wild-olive - grass landscape mosaic
}

\author{
Nicola Montaldo $^{\mathrm{a},}{ }_{*}$, Matteo Curreli ${ }^{\text {a, }}$, Roberto Corona ${ }^{\mathrm{a}}$, Ram Oren ${ }^{\mathrm{b}, \mathrm{c}, *}$ \\ a Dipartimento di Ingegneria civile, ambientale e architettura, Università di Cagliari, Via Marengo, 3, I-09123 Cagliari, Italy \\ ${ }^{\mathrm{b}}$ Nicholas School of the Environment \& Pratt School of Engineering, Duke University, Durham, NC 27708, USA \\ ${ }^{c}$ Department of Forest Sciences, University of Helsinki, FI-00014, Finland
}

\section{ART ICLE INFO}

Keywords:

Evapotranspiration

Soil moisture

Tree transpiration

Vapor pressure deficit

Wild olive

\begin{abstract}
A B S T R A C T
Dry regions are typically characterized by heterogeneous ecosystems where trees are competing with the surrounding grasses for limited amount of water. In these regions, evapotranspiration (ET) is the leading loss term in the soil water budget, and its estimate, and the dynamic contribution of each ET component (i.e. tree and grass transpiration, and dry bare soil and wet surface evaporation), are still poorly quantified. In a typical heterogeneous Mediterranean ecosystem in Sardinia, we combined eddy-covariance estimates of ET with sap flux and energy balance estimates of wild-olive tree transpiration, a common tree species of the region, and with modeled evapotranspiration from the seasonal grass. Trees located in the southern edge of clumps, thus receiving more radiation, transpired more and showed a greater sensitivity to increasing vapor pressure deficit and soil moisture than trees located in clump centers or northern edges. Transpiration of the tree clumps in the footprint $\left(E_{\mathrm{t}}\right)$, summed up with the modeled evapotranspiration components of the surrounding grass (mostly transpiration during the wet season and evaporation during the dry season), matched latent heat flux measurements, lending confidence in the estimates. Proper accounting for heterogeneity of sources within the eddy covariance footprint seems to have overcome potential errors from not preserving an important assumption of the method, the land-surface homogeneity, highlighting the methods reliability in such inhomogeneous ecosystem. Compared to ET, $E_{t}$ of wild olives was nearly constant over the hydrologic year, insensitive to variation in soil moisture and atmospheric conditions. In contrast, under favorable spring environmental conditions (radiation, vapor pressure deficit, and soil moisture), the pasture leaf area transpires at high rates, contributing to, and dominating the high ET during that season. Conversely, in dry periods, when evapotranspiration from the grass cover is dominated by low evaporation from the, principally, bare soil, $E_{t}$ dominants ecosystem $E T$.
\end{abstract}

\section{Introduction}

Dry regions are typically characterized by heterogeneous ecosystems where trees or tree clumps are competing with the surrounding grasses for limited amount of water (Scholes and Archer, 1997; Sankaran et al., 2005; Breshears, 2006; Detto et al., 2006; Montaldo et al., 2008; Villegas et al., 2014). In these regions, tree cover and its spatial patterns are variable, depending on the water availability and incoming radiation (Sankaran et al., 2005), both of which respond to topographic, climatic and edaphic factors, and ultimately produce the tree-grass mosaic on the landscape (Breshears, 2006; Moore and Heilman, 2011; Villegas et al.,

2014).
In turn, the characteristics of the woody plant-grass mosaic influence the land surface fluxes, and these have different seasonal dynamics in patches of tree canopy and adjacent inter-canopy surface (Breshears, 2006). In semi-arid and arid regions, evapotranspiration (ET) is the leading loss term in the soil water budget (Reynolds et al., 2000; Rodriguez-Iturbe, 2000; Baldocchi et al., 2004; Kurc and Small, 2004; Maselli et al., 2004). Efforts have been invested in estimating ET in these ecosystems, yet the contribution of each ET component to its seasonal dynamics (e.g., tree and grass transpirations, bare soil evaporation), especially during dry periods, are often poorly quantified (Baldocchi et al., 2004; Kurc and Small, 2004; Detto et al., 2006; Griebel et al., 2016; Chebbi et al., 2018; Stoy et al., 2019).

\footnotetext{
* Corresponding authors.

Email addresses: nmontaldo@unica.it (N. Montaldo); ramoren@duke.edu (R. Oren)
} 
Estimating the components of $E T$, especially in heterogeneous systems during conditions of low flux, is far from simple (Raz-Yaseef et al., 2010; Villegas et al., 2014). Even over a relatively homogeneous forests, for $E T$ components to sum up to total $E T$, estimated using the eddy-covariance method $\left(E T_{E C}\right)$ (Baldocchi, 2003, 2008), tree transpiration must be scaled from sap flux measurements to the eddy-covariance footprint based on the spatial distribution of sapwood or leaf-area index (Wilson et al., 2001; Bovard et al., 2005; Oren et al., 2006; Oishi et al., 2008; Domec et al., 2012). Variation of leaf-area index and, even more, of land-cover and its surface properties, represent a departure from one of the principal assumptions of the eddy-covariance method, the assumption of planar-homogeneity of the monitored land surface (Finnigan, 2004; Belcher et al., 2012; Griebel et al., 2016). This assumption is greatly strained when the method is employed for estimating fluxes over patchy ecosystems, especially when the surface soil dries, and the inter-canopy pasture species senesce. With lengthening periods between appreciable rain events, the footprint is increasingly heterogeneous as the soil dries and the landscape transforms into patches of trees continuing to emit water vapor, surrounded by bare soil (or areas mostly covered by dry grass) contributing negligibly to evaporation. Furthermore, in such periods, and especially where tree cover is low, as is typical of ecosystems in these regions (e.g., < $40 \%$ of the mosaic; Baldocchi et al., 2004; Kurc and Small, 2004; Detto et al., 2006; Montaldo et al., 2008), the mean ecosystem ET is low, and measurement uncertainties may be similar to the ET estimates.

Not only are estimates of total ET uncertain under such spatial and temporal conditions, but so are the components of ET (Stoy et al., 2019). In dry ecosystems, depending on the season, each component of ET may become important, or even dominant; these include rainfall interception by, and evaporation from wet tree canopy elements and soil-grass surface $\left(E_{w}\right)$, evaporation from dry bare soil $\left(E_{b s}\right)$, and transpiration of tree canopy $\left(E_{t}\right)$ and non-woody vegetation (mainly grass, $E_{g}$ ). Quantifying the seasonality of $E_{t}$ can be based on properly measured and scaled sap-flux (Oren et al., 1998). For such scaling, finer scale, systematic variation in sap flux must be accounted for, including variation in flux radially reflecting decreased activity with depth in the sapwood (Phillips et al., 1996), azimuthally around stems reflecting the intensity of light on the crown (Oren et al., 1999; Moon et al., 2015; Komatsu et al., 2016), and tree distance from more illuminated edges (Cienciala et al., 2002; Herbst et al., 2007; Wright et al., 2012). Indeed, trees positioned on the southern edge of clumps in patchy landscapes may be better illuminated (in the northern hemisphere) than others, perhaps transpiring more while moisture is amply available, yet experiencing the effects of drought stress earlier than trees in other positions. Thus, employing the most commonly used method for measuring sap flux, the thermal dissipation probe (Granier, 1987), requires overcoming errors associated with calibration (Köstner et al., 1998; Steppe et al., 2015), and careful scaling to minimize uncertainty. Because estimating $E_{t}$ reliably is essential for assessing its importance as component of $E T$, especially during the dry season, an independent verification of this value would decrease the uncertainty of subsequent analyses. Such verification can be made based on the energy balance (Fritschen and Simpson, 1989; Garratt, 1992). This does not imply that the energy balance approach is without uncertainty (Foken, 2008), but to suggest that, if two very different approaches produce a similar estimate of $E_{t}$, results from subsequent analyses are more reliable.

In patchy landscapes, tree clumps may reach for water horizontally under areas covered with highly seasonal vegetation (House et al., 2003; Breshears, 2006; Breshears et al., 2009). Although evapotranspiration from these patches can be high during the wet season, it decreases during the dry season to the low rate of evaporation from dry vegetation and bare soil. Evapotranspiration from non-woody patches during both wet and dry seasons are most readily estimated with the help of models, each of which still contains uncertainties (Franks et al., 1997; Montaldo et al., 2003, 2007). Because of the uncertainties involved in the estimates of these quantities, it is advisable to independently estimate each, sum up the components of $E T$, and compare to the lumped value of $E T$ obtained from eddy-covariance measurements (Schäfer et al., 2002; Montaldo et al., 2008). This also requires to scale sap flux measurements to $E_{t}$ estimate at the same footprint of the eddy-covariance based ET estimate (Williams et al., 2004; Oishi et al., 2008). To summarize, in these heterogeneous ecosystems, the partitioning of $E T$ into its components is still a challenge, particularly during the dry season (Raz-Yaseef et al., 2010; Villegas et al., 2014; Chebbi et al., 2018; Stoy et al., 2019). Yet, such partitioning is essential for quantifying the dynamic seasonal contribution to ET of each of its components.

Detto et al. (2006) investigated a typical heterogenous Mediterranean ecosystem located at Orroli in Sardinia (Italy; Montaldo et al., 2008, 2013), a patchy mixture of trees (mainly wild olive, Olea sylvestris) and grass growing on thin soil ( $\sim 0.17 \mathrm{~m}$ depth) above a fractured basalt. Comparing $E T_{E C}$ with $E T$ estimated based on the energy balance over a single wild-olive patch, they suggested that $E_{t}$ is the likely primary component of ET during the dry seasons, highlighting the need for estimating the contribution of this component.

Here, in a typical heterogeneous Mediterranean ecosystem in Sardinia, we combined eddy-covariance estimates of $E T$ with (i) sap flux and energy balance estimates of wild-olive tree transpiration, a common tree species of the regions (Lumaret and Ouazzani, 2001; Terral et al., 2004), and (ii) modeled evapotranspiration from the seasonal grass, quantifying the seasonal amounts and dynamics of ET and its components. In scaling sap flux to $E_{t}$, we accounted for heterogeneities of transpiration within clumps (i.e., position in clumps), and the clump area within the footprint area. Our objectives were: (1) to quantify the transpiration of a common Mediterranean tree species, the wild olive, in contrasting atmospheric and soil moisture conditions, and its spatial variability within clumps; (2) to test the accuracy of the eddy-covariance method estimating $E T$ in spatiotemporally heterogeneous landscape, with spatial heterogeneity introduced by the tree-grass mosaic, and temporal heterogeneity introduced by dry periods affecting the activity of grassy areas more than tree clumps; and (3) to quantify the dynamics of the contribution of each ET component during the hydrologic year.

\section{Materials and methods}

\subsection{Setting}

The Orroli field site is located in east-central Sardinia $\left(39^{\circ} 41^{\prime} 12\right.$. 57" N, 9 $9^{\circ} 16^{\prime} 30.34^{\prime \prime}$ E, 500 m a. s. 1.; details in Detto et al., 2006, 2008; Montaldo et al., 2008, 2013). The landscape is a patchy mixture of tree clumps forming canopy cover over $\sim 33 \%$ of the footprint area, $1.5 \mathrm{~km}^{2}$ on a gently sloping ( $\sim 3^{\circ}$ from NW to SE) plateau, while inter-clump zones are covered by herbaceous and grass species during high moisture periods, becoming dry bare soil surface during the rainless summer months. The dominant trees species is wild olive in patches ranging in height $3.5-4.5 \mathrm{~m}$, with scattered 6-7 $\mathrm{m}$ tall emergent individuals of cork oak (Quercus suber), and shorter shrubs (Asparagus acutifolius and Rubus ulmifolius); vines (Crataegus azarolus and Smilax aspera) often climb the trees.

The climate at the flux site is maritime Mediterranean, with a mean annual precipitation (1922-2007) of $643 \mathrm{~mm}$, and mean July precipitation of $11 \mathrm{~mm}$. Mean annual air temperature $\left(T_{\mathrm{a}}\right)$ is $14.6^{\circ} \mathrm{C}$, with mean July $T_{\mathrm{a}}$ of $23.7^{\circ} \mathrm{C}$. The soil ranges $0-50 \mathrm{~cm}$ in depth, aver- 
aging $17 \mathrm{~cm} \pm 6 \mathrm{~cm}$ (standard deviation, SD) above a fractured basalt, thus quickly plunging into water-limited conditions during the rainless summer (Detto et al., 2006; Montaldo et al., 2008). The soil is silt loam (19\% sand, $76 \%$ silt, $5 \%$ clay) with a bulk density of $1.38 \mathrm{~g} / \mathrm{cm}^{3}$, and a porosity of $53 \%$.

\subsection{Soil and micrometeorological measurements}

Seven frequency domain reflectometer probes (FDR, Campbell Scientific Model CS-616) were inserted in the soil close to the tower (3.3-5.5 $\mathrm{m}$ away) to estimate moisture $(\theta)$ in the thin soil layer. Two of these were buried horizontally (at 5 and $15 \mathrm{~cm}$ depth, in an open patch), three were installed vertically (i.e. average of $\sim 30 \mathrm{~cm}$ depth, two in open patch and one under a tree canopy), and two were installed obliquely (i.e. average of $\sim 20 \mathrm{~cm}$ depth, one in open patch and one under a tree canopy). FDR calibration ( $\theta=2.456-7.135 \tau+6.701 \tau^{2}-1.884 \tau^{3}$, where $\tau$ is the output period in milliseconds) was made using 15 periodic gravimetric water content samples taken over a wide range of $\theta\left(0.08-0.52 \mathrm{~m}^{3} \mathrm{~m}^{-3}\right)$ near the probes, and along the soil profile.

Three-dimensional time series sampling of wind velocity, temperature, and $\mathrm{CO}_{2}$ and water vapor concentration at $10 \mathrm{~Hz}$ were averaged over $30 \mathrm{~min}$ intervals. These data were used to estimate $E T$ and sensible heat flux based on the standard eddy-covariance method (Baldocchi, 2003). The measurements were made with a Campbell Scientific CSAT-3 tri-axial sonic anemometer, and a Licor-7500 $\mathrm{CO}_{2} / \mathrm{H}_{2} \mathrm{O}$ infrared gas analyzer, positioned adjacent to each other at the top of the $10 \mathrm{~m}$ tall tower. The effect of the gentle slope of the plateau was removed by utilizing the conventional planar fit method, and the Webb-Pearman-Leuning adjustment was applied (Detto et al., 2006, 2008).

A Vaisala HMP45 sensor was used to measure $T_{\mathrm{a}}$ and relative humidity $(R H)$. Vapor pressure deficit, $D$ was calculated as $D=e^{*}\left(T_{\mathrm{a}}\right)(1-R H)$, where the saturation vapor pressure $e^{*}$ is related to $T_{\mathrm{a}}$ through the Clausius-Clayperon equation (Stull, 1988). When using daily mean $D$ to explain variations in daily flux, $D$ was averaged over daytime hours and normalized to $D_{z}[\mathrm{kPa}$ ] by the day-length [h] divided by 24 , accounting for changing daily light period over the year (Oren et al., 1996; Tor-ngern et al., 2017).

Two infrared transducers, IRTS-P (Apogee Instrument, accuracy of $0.3^{\circ} \mathrm{C}$ ) were used to measure the surface temperature $\left(T_{s}\left[{ }^{\circ} \mathrm{C}\right]\right)$ of the different land cover components. One IRTS-P was positioned to monitor the canopy skin temperature of a wild olive clump at $3.5 \mathrm{~m}$ height aboveground with a canopy view zenith angle of $\sim 70^{\circ}$, focusing on the southern side of a clump; a second sensor monitored bare soil and grass (depending on the season) at $1.6 \mathrm{~m}$ above the ground with a view zenith angle of $\sim 50^{\circ}$ The incoming and outgoing shortwave and longwave radiation components used to derive net radiation, $R_{\text {net }}\left[\mathrm{W} \mathrm{m}{ }^{-2}\right]$, were measured with a CNR-1 (Kipp \& Zonen) integral radiometer with a hemispherical field of view, positioned at $10 \mathrm{~m}$. Photosyntetically active radiation (PAR, [mmol m $\left.{ }^{-2} \mathrm{~d}^{-1}\right]$ ) was measured with the LI-190 Quantum Sensor (Licor). Soil heat flux was measured at two different locations close to the tower, one in an open patch ( $4 \mathrm{~m}$ from the tower) and one under a tree canopy of wild olive $(5.5 \mathrm{~m}$ from the tower), with thermopile plates, HFT3 (REBS), buried at $8 \mathrm{~cm}$ below the soil surface. Two thermocouples (per plate) were buried at 2 and $6 \mathrm{~cm}$, and one frequency domain reflectometer probe per plate was buried horizontally at $5 \mathrm{~cm}$, as needed to estimate changes in the stored energy above the plates (see HFT3 instruction manual edited by Campbell Sci.)

\subsection{Sap flow measurements}

Sap flow was monitored using Granier-type heat dissipation sensors (Granier, 1987). Sap flux sensors measure the temperature differential ( $\Delta T$, recorded in $\mathrm{mV}$ ) between the paired heated and unheated probes, and xylem water flux, $J_{s}\left[\mathrm{~g} \mathrm{~m}^{-2} \mathrm{~s}^{-1}\right]$, is given by (Granier, 1987):

$J_{s}=11910^{-6}\left(\frac{\Delta T_{\max }-\Delta T}{\Delta T}\right)^{1.231}$

where $\Delta T_{\max }$ is the maximum temperature differential at which sap flux is zero (Granier, 1987). It is highly recommended to calibrate the sensors for each species, and often for different conditions (Steppe et al., $2015)$. However, the wild olive wood is very dense $\left(\sim 1 \mathrm{~g} / \mathrm{cm}^{3}\right)$, and flow rates were very low under pressure; we therefore opted to use the original parameters. We tested whether sap flux estimate is reasonable, scaling the flux to ground-based transpiration (see below) and comparing to energy balance-based estimate obtained at the southern edge of a wild olive clump near the eddy covariance tower.

Before installing the sensors, we investigated the trees and clumps in the eddy-covariance flux footprint to obtain necessary scaling variables. We measured the diameter ( $\varnothing$, in $\mathrm{cm}$, at height of $0.4 \mathrm{~m}$ aboveground) of 1615 trees in 21 clumps (all stems $\geq 1 \mathrm{~cm}$ ) within the footprint, in the two prevailing wind directions from the tower [mistral (north-west) and sirocco (south-east); Montaldo and Oren, 2016]. Based on these we selected nine trees of diameters representing the range of these found on the footprint to determine sapwood depth from tree cores (after Oishi et al., 2008).

We installed sap flux sensors at the height of $40 \mathrm{~cm}$ in the trunks of 33 trees positioned in 15 clumps within the eddy-covariance footprint [mainly north-west and south-east of the tower, the main wind directions in Sardinia (Mistral and Sirocco, respectively; Montaldo and Oren, 2016)]. Each pair of sensors was $20 \mathrm{~mm}$ in length and the heated element received a constant power of $0.2 \mathrm{~W} . \Delta T$ for each sensor pair was measured at $1 \mathrm{~s}$ intervals, averaged over $30 \mathrm{~min}$ and stored on three CR3000 dataloggers (Campbell Scientific, Logan, UT, USA). Sap flux was measured from August 22, 2014 to July 9, 2017. Time series of the sap flux measurements were not continuous due to interruptions in the power supply, downtime for maintenance, and sensor failure. Of the 33 sensors, 11 satisfied the following conditions: 1) the sensor produced clean and reasonable patterns in the data for more than 70 days, 2) the sensor had operated over periods in which daily mean $\theta$ ranged from at least 0.08 to 0.25 , and 3 ) the sensor had operated over periods in which the half-hourly vapor pressure deficit ranged from $<0.5 \mathrm{kPa}$ to $>4.0 \mathrm{kPa}$. The selected 11 monitored trees represented eight of the 21 clumps, and the tree size distribution within the footprint $(\varnothing$ ranged $5.0-13.0 \mathrm{~cm}$ [Table 1], with mean of $8.3 \mathrm{~cm}$ and SD of $2.1 \mathrm{~cm}$, similar [ $p=0.12]$ to that of the 1615 trees [mean $\emptyset 7.0 \mathrm{~cm}$ and SD of $2.8 \mathrm{~cm}$ ]). The sapwood area of trees with $\emptyset \geq 5.0 \mathrm{~cm}$, the minimum reasonable diameter for our heat dissipation probe, represent $90.6 \%$ of the total sapwood area. The positions inside the clump (south, center, or north), the diameters at $40 \mathrm{~cm}$ above ground, and the soil depth near each of the 11 trees monitored for sap flux, are provided in Table 1.

Each of the study years contained periods of missing data. To capture the typical seasonal dynamics of sap-flux, we patched together the available portions of the time series from 2014-2016, creating a continuous series beginning in spring (March 20) and ending in fall (November 19). We also used the data from the even drier spring and summer of 2017. 
Table 1

Tree characteristics and location within clumps represented by the 11 thermal dissipation probes used for measuring sap flux. Position refers to the location of tree in clumps ( $\mathrm{S}=$ southern edge, $\mathrm{C}=$ clump center, $\mathrm{N}=$ northern edge), $\emptyset$ is tree diameter $40 \mathrm{~cm}$ aboveground, $d_{s}$ is the depth of soil near the tree base, $A_{s w}$ is the sapwood area.

\begin{tabular}{lllll}
\hline Sensor & Position & $\emptyset[\mathrm{cm}]$ & $A_{s w}\left[\mathrm{~cm}^{2}\right]$ & $d_{s}[\mathrm{~cm}]$ \\
\hline 1 & $\mathrm{~S}$ & 13.0 & 117.90 & 19.3 \\
3 & $\mathrm{C}$ & 5.0 & 12.00 & 22.6 \\
9 & $\mathrm{C}$ & 8.4 & 41.40 & 21.8 \\
10 & $\mathrm{C}$ & 5.9 & 22.20 & 19.5 \\
14 & $\mathrm{~N}$ & 9.3 & 53.30 & 16.0 \\
15 & $\mathrm{~N}$ & 8.7 & 44.80 & 13.1 \\
19 & $\mathrm{~S}$ & 8.1 & 41.40 & 24.3 \\
20 & $\mathrm{~N}$ & 8.0 & 41.40 & 24.0 \\
25 & $\mathrm{~S}$ & 7.1 & 32.00 & 27.8 \\
28 & $\mathrm{~N}$ & 9.5 & 59.90 & 20.7 \\
33 & $\mathrm{C}$ & 8.0 & 41.40 & 16.1 \\
\hline
\end{tabular}

In scaling sap-flux to the eddy-covariance footprint, we used data from 21 clumps selected within the prevailing directions in the footprint (including the 15 clumps in which sap flux sensors were installed, and additional six clumps farther from the tower). In each clump we estimated the ratio $A_{s w} / A_{g}\left(A_{s w}\right.$ is the total tree sapwood area of the clump, and $A_{g}$ is the clump's ground area, represented by its canopy projection). Sap flux, $J_{s}$, was scaled to tree transpiration within the clump area, $E_{t}^{S F}$, with $A_{s w} / A_{g}$ (Oren et al., 1998):

$E_{t}^{S F}=J_{s} \frac{A_{s w}}{A_{g}}$

\subsection{Evapotranspiration estimate}

Using the eddy-covariance method the ecosystem evapotranspiration was estimated at the scale of the flux footprint. The closure of the eddy-covariance ET budget was evaluated using the two-dimensional footprint model of Detto et al. (2006) for upscaling the components within the eddy-correlation contributing land-cover area:

$$
E T=F_{f p, t} E_{t}+F_{f p, g} E_{g}+F_{f p, b s} E_{b s}+E_{w}+\delta
$$

where $F_{f p, t} F_{f p, g}$, and $F_{f p, b s}$ are the fractions of tree cover, grass cover and bare soil in the flux footprint respectively [estimated using Eq. (4) of Detto et al., 2006], and $E_{w}$ is the wet canopy (or surface) evaporation. Note that $F_{f p, b s}$ includes soil under the tree canopy (Raz-Yaseef et al., 2010 ), with $E_{b s}$ reduced by $40 \%$ under the canopy due to lower radiation under the high LAI (Jackson and Wallace, 1999). The pasture evapotranspiration contribution, $E_{p}$, combines two components of $E T$ $\left(E_{p}=F_{f p, g} E_{g}+F_{f p, b s} E_{b s}\right)$. The residual, $\delta$, must be relatively small to lend confidence in the estimates of the components and the total ET. For estimating the fractions of land cover components in the site, a multispectral high spatial resolution $(2.8 \mathrm{~m})$ Quickbird satellite images (DigitalGlobe Inc.) was acquired (08/03/2003) (Detto et al., 2006). A supervised classification scheme based on the parallelepiped algorithm (Montaldo et al., 2008) allows distinguishing trees from bare soil in the image (grass was absent on the dry August 2003). Further details, on how the footprint model and the high-resolution satellite images were used in upscaling component flux to the relevant footprint of the micrometeorological observations, can be found in Detto et al. (2006) and Montaldo et al. (2008). The fraction of area covered by tree canopy and pasture was estimated half-hourly based on the eddy-covariance footprint, thus varies in time with the footprint.

Upscaling the sap-flux measurements to the eddy-covariance footprint scale tree transpiration $\left(E_{t, f p}\right)$ was accomplished by multiplying $E_{t}^{S F}$ by $F_{f p, t}$ following (3). Following Detto et al. (2006) approach, we also estimated the tree transpiration with the energy balance method [( $\left.E_{t}^{E B}\right)$, Eqs. (7)-(14) of Detto et al. (2006)], which is based mainly on canopy $T_{s}$, wind velocity, air temperature and radiometer measurements. Given the location of the tower relative to a nearby clump, and the availability of only one infrared transducer for measuring $T_{s}$ of the clump, $T_{s}$ observations were available for only the southern side of a clump, and $E_{t}^{E B}$ estimates were available for trees at that edge only. We estimated $E_{b s}$ and $E_{g}$ using a simple approach (Detto et al., 2006): $E_{b s}=\alpha P E$ (where $P E$ is the potential evapotranspiration), and $E_{g}=\beta P E$ [with $\alpha=-9.815 \theta^{3}+9.173 \theta^{2}-0.082 \theta$ (Parlange et al., 1999), and $\beta=(\theta-0.08) / 0.10$, if $\theta \leq 0.2$ and $\beta=1$ if $\theta>0.2$ (Montaldo et al., 2008)]. The two simple models, already tested in Montaldo et al. (2008), were further evaluated based on short-term observations using the same energy balance method for estimating $E_{g}$ and $E_{b s}$ [Eqs. (7)-(14), Detto et al. (2006)]. The IRTS-P monitored bare soil and grass, in proportions depending on the season; we limited the evaluation such that (1) the energy balance-based $E_{b s}$ was estimated only when the grass foliage senesced (summer) and $T_{s}$ represented bare soil only, or (2) the energy balance-based $E_{g}$ was estimated only when the grass foliage was dense, green and active (spring) and $F_{f p, b s}$ was negligible. $E_{w}$ was set to the rainfall interception, with storage capacity of 0.2 $L A I$ (Noilhan and Planton, 1989), where $L A I$ is the leaf area index. $L A I$ was estimated for both grass and tree canopy separately using the land surface-vegetation dynamic model of Montaldo et al. (2008), calibrated for the Orroli site.

Potential evapotranspiration $(P E)$ was estimated based on the Priestley-Taylor equation [e.g., Brutsaert, 1992, equation (10.23)], with the $\alpha_{e}$ Priestley-Taylor coefficient set at 1.26 (Brutsaert, 1982; Detto et al., 2006).

\section{Results}

Meteorological forcing of the second time-series (2017) was different in spring (Fig. 1) from that observed in 2016, because the second spring was drier than usual $(35 \mathrm{~mm}$ precipitation compared to a mean of $120 \mathrm{~mm}$ over 2003-2017), impacting both $D_{z}$ and $\theta$ values. In the early part of May 2016, several rain events brought the soil to near saturation, and $D_{z}$ decreased to values lower than $0.4 \mathrm{kPa}$, lower than in spring 2017 during which soil moisture was approaching values typically seen only in summer. In summer, 2015, $D_{z}$ reached $2 \mathrm{kPa}$ even though three large rain events increased soil moisture in June and July (Fig. 1). $D_{z}$ decreased in fall along with $P A R$ as radiation decreased below that of spring, and soil moisture increased with precipitation (Fig. 1). The three seasons (spring, summer and fall) are characterized by different combinations of meteorological and edaphic conditions, facilitating assessment of the responses of seasonal ET, and its components.

\subsection{Transpiration at tree scale}

Scaling sap-flux to trees and clumps using Eq. (2), required that we quantify tree and clump properties. Tree diameters of 1270 trees in 11 clumps within the footprint ranged from $1 \mathrm{~cm}$ (the minimum size measured) to $19 \mathrm{~cm}$, averaging $6 \mathrm{~cm}(\mathrm{SD}=3.1 \mathrm{~cm})$. Cores of trees ranging in diameter from $6 \mathrm{~cm}$ to $14 \mathrm{~cm}$ produced estimated sapwood depths ranging $2.70-7.05 \mathrm{~cm}$, averaging $3.96 \mathrm{~cm}(\mathrm{SD}=1.27 \mathrm{~cm})$. From these measurements we estimated $A_{s w}$ and developed a relationship between $A_{s w}$ and $\varnothing\left(A_{s w}=0.6 \varnothing^{2.1} ; \mathrm{R}^{2}=0.99\right)$; the relationship was similar to a more linear representation for irrigated Olea europaea trees of diameter $>4 \mathrm{~cm}$ (Ramos and Santos, 2009). The allometric $A_{s w^{-}} \varnothing$ relationship was used to estimate sapwood depth before sensor installation. Extrapolating the $A_{s w^{-}} \emptyset$ function to the minimum diameter considered in scaling $(1 \mathrm{~cm})$, produced an estimate of 

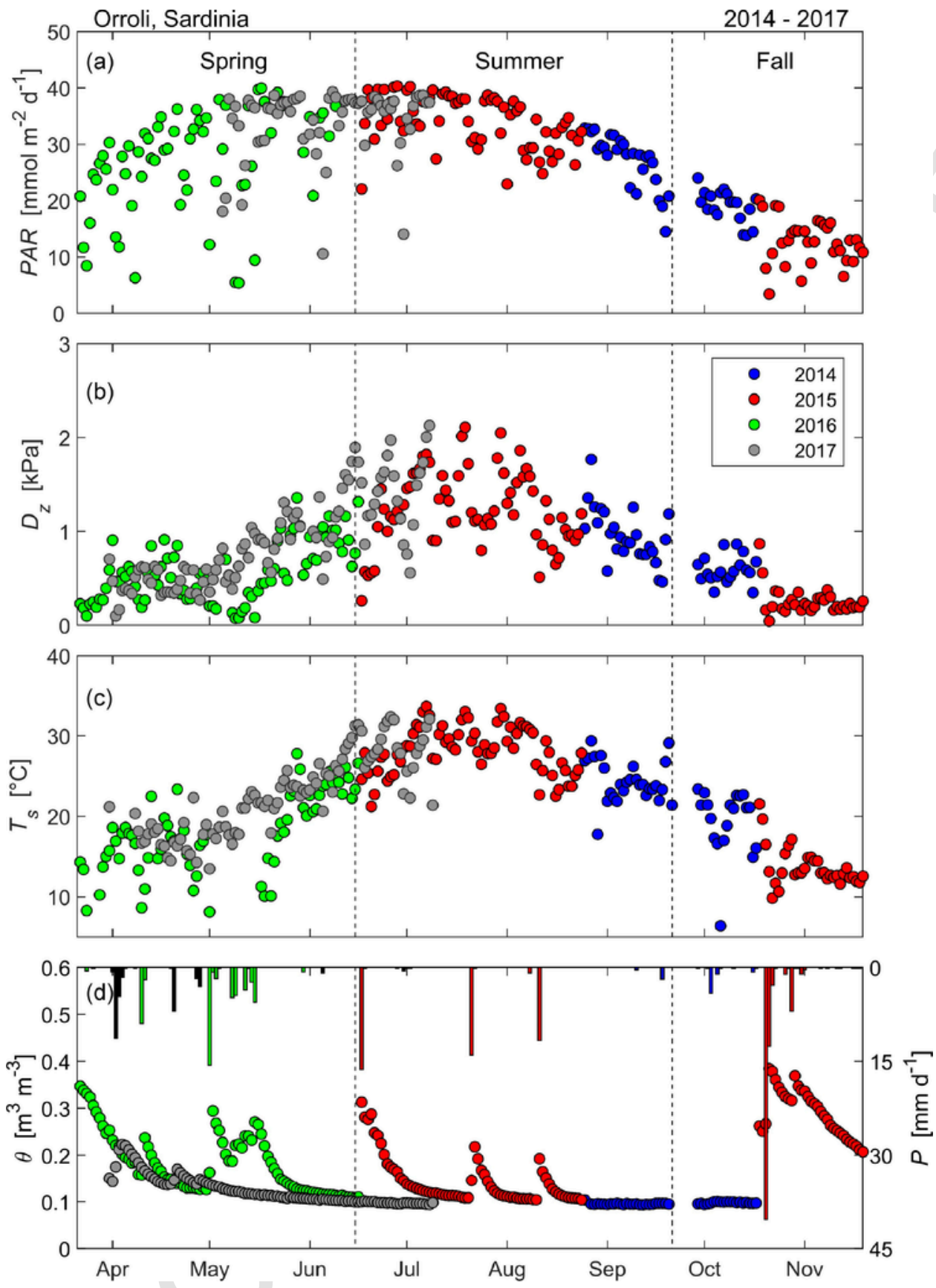

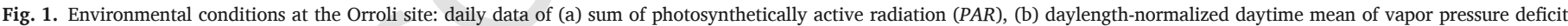

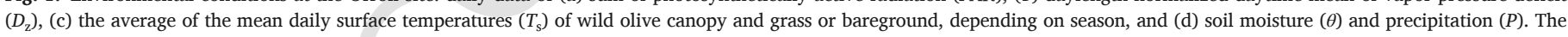
boundaries of the seasons are indicated by vertical dashed lines.

sapwood diameter of $0.88 \mathrm{~cm}$, consistent with observation of thin bark $(\sim 0.06 \mathrm{~cm})$ and no visible heartwood in such small diameter individuals.

Using the $A_{s w^{-}} \emptyset$ function, we estimated the sapwood area of each stem in the 11 clumps. The canopy area of these clumps was $\sim 70-115 \%$ of the total tree canopy area in the wind velocity- and direction-dependent variable footprint area; clumps varied in number of trees and size, averaging $127 \mathrm{~m}^{2}\left(\mathrm{SD}=50 \mathrm{~m}^{2}\right)$. The mean of $A_{s w} / A_{g}$ was 0.00195 $(\mathrm{SD}=0.00056)$, showing relatively low variation $(\mathrm{CV}=21 \%)$, and was used for scaling sap flux to $E_{t}$ in all wild olive clumps in the footprint (using Eq. (2)). Based on the $A_{s w^{-}} \emptyset$ relationship, sapwood depth was greater than the sensor length in all trees, and no correction was required (Clearwater et al., 1999). In scaling, we assumed that $J_{s}$ in sapwood deeper than the sensor length is similar to that monitored, because the sapwood did not extend much beyond the sensors in most individuals in the clumps. In total, the outer $20 \mathrm{~mm}$ of the sapwood represented $84 \%$ (SD $=15 \%$ ) of the sapwood area of the 11 clumps.

We analyzed the sap flux of the 11 monitored trees (in 8 clumps, see Section 2.3. and Table 1), searching for known systematic sources of variation to improve the accuracy of scaling. Because, based on the results above, scaling $J_{s}$ to clump transpiration is simply a matter of multiplying by a constant $A_{s w} / A_{g}$ (Eq. (2)), we chose to do it at this stage of the analysis, so units are comparable among variables. We found that the daily mean $E_{t}^{S F}$ of the 11 trees was unrelated to tree diameters $(p=0.39$, and Pearson correlation coefficient, 
$\rho=0.28)$, and soil depth near the base $(p=0.57$ and $\rho=-0.19)$ in both dry $(\theta<0.12)$ and wet $(\theta \geq 0.12)$ soil conditions. However, $E_{t}^{S F}$ was affected by the position of trees in clumps (Fig. 2). The following averages provided a rough idea of the difference in transpiration imposed by tree location within clumps: trees at southern edges of clumps transpired more $(2.01 \mathrm{~mm} / \mathrm{d}, \mathrm{SD}=0.80 \mathrm{~mm} / \mathrm{d})$ averaging data of 191 days than trees at the center $(1.16 \mathrm{~mm} / \mathrm{d}, \mathrm{SD}=0.43 \mathrm{~mm} / \mathrm{d})$ and the northern edges $(1.21 \mathrm{~mm} / \mathrm{d}, \mathrm{SD}=0.41 \mathrm{~mm} / \mathrm{d}) . E_{t}^{S F}$ of trees at the southern edge of clumps was also higher under high soil moisture conditions $(2.13 \mathrm{~mm} / \mathrm{d}$,
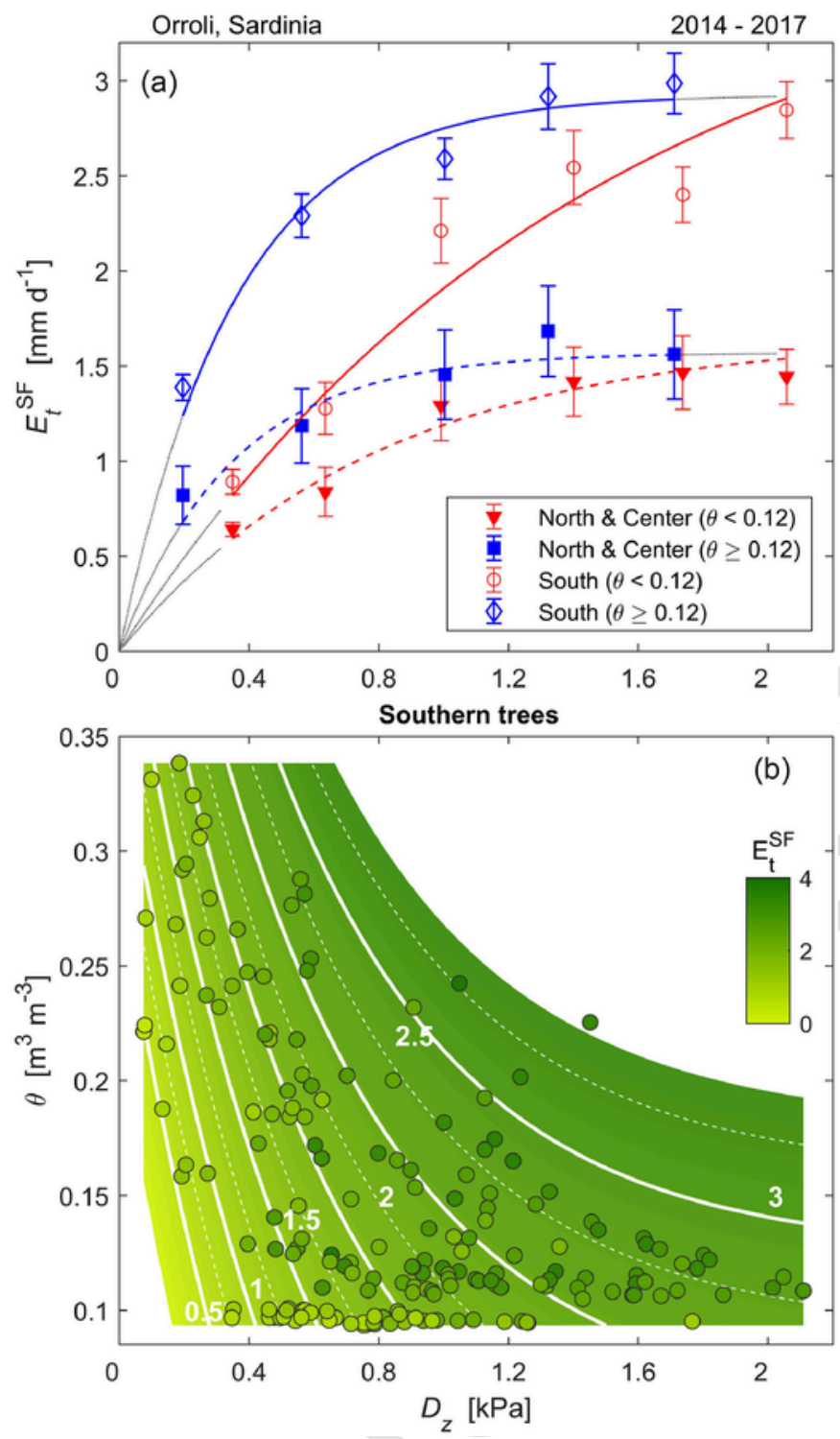

Fig. 2. (a) The sensitivity of sap flux - based tree transpiration $\left(E_{t}^{S F}\right)$, scaled to ground area from 11 thermal dissipation probes (using sapwood area per unit of ground area) to daylength-normalized daytime vapor pressure deficit $\left(D_{\mathrm{z}}\right)$, depended on the location of trees in the clump [northern-edge and clump-center behaved similarly and combined to $n=8$ trees, different from southern-edge $n=3$ trees]; the sensitivity of $E_{t}^{S F}$ to $D_{z}$ of southern-edge trees only depended on soil moisture $(\theta)$. Transpiration data (191 daily values) have been partitioned to two classes of soil moisture conditions $(\theta<0.12$ and $\theta \geq 0.12$ ), and further into six intervals (bins, $0-0.4 \mathrm{kPa}, 0.4-0.8 \mathrm{kPa}, 0.8-1.2 \mathrm{kPa}$, $1.2-1.6 \mathrm{kPa}, 1.6-2.0 \mathrm{kPa}, 2.0-2.4 \mathrm{kPa}$ ) of $D_{z}$. Shown are the sap-flux means (with 1 standard error) in each bin of $D_{z}$, plotted against the bin mean of $D_{z}$, of the two soil moisture classes, and fitted exponential lines (equations are in the text). (b) A fitted continuous surface of the $E_{t}^{S F}$ of southern-edge trees with $\theta$ and $D_{\mathrm{z}}$. Circles are the observed daily values of $E_{t}^{S F}$; white lines are the fitted isolines of $E_{t}^{S F}$.
$\mathrm{SD}=0.79 \mathrm{~mm} / \mathrm{d}$ at $\theta \geq 0.12)$ than in dry conditions $(1.95 \mathrm{~mm} / \mathrm{d}$, $\mathrm{SD}=0.79 \mathrm{~mm} / \mathrm{d}$ ), while $E_{t}^{S F}$ of trees in the center and northern edge were insensitive to soil moisture $(1.12 \mathrm{~mm} / \mathrm{d}, \mathrm{SD}=0.34 \mathrm{~mm} / \mathrm{d}$ at $\theta \geq 0.12$, and $1.19 \mathrm{~mm} / \mathrm{d}, \mathrm{SD}=0.47 \mathrm{~mm} / \mathrm{d}$ at $\theta<0.12 ; E_{t}^{S F}$ relations with $D_{z}$ for $\theta<0.12$ and $\theta \geq 0.12$ are not significantly different, $p>0.3$; Fig. 2). However, the transpiration rates were not random, but were affected by the driving force indicated by $D_{z}$ (Fig. 2), and in some cases by the resistance to water uptake, indicated by $\theta . E_{t}^{S F}$ data of the trees at southern edge and those in the clump center and northern edge have been first partitioned based on soil moisture conditions $(\theta<0.12$ and $\theta \geq 0.12$ ), then furthered broken into six intervals (bins) of $D_{z}$ (Fig. 2a). Thus analyzed, $E_{t}^{S F}$ of trees at southern edges increased more rapidly with $D_{z}$ under moist $\left[E_{t}^{S F}=2.9\left(1-\mathrm{e}^{-2.8 D z}\right), \mathrm{R}^{2}=0.64\right]$ than under dry soil $\left[E_{t}^{S F}=3.8\left(1-\mathrm{e}^{-0.68 D z}\right), \mathrm{R}^{2}=0.55\right]$; the values became more similar at high $D_{z}$ (Fig. 2a) reaching a plateau of $\sim 2.5 \mathrm{~mm} /$ d. $E_{t}^{S F}$ of northern edge and clump center trees had a similar sensitivity to $D_{z}$ under low soil moisture conditions $\left[E_{t}^{S F}=1.57\left(1-\mathrm{e}^{-2.90}\right.\right.$ $\left.\left.{ }^{D z}\right), \mathrm{R}^{2}=0.46\right]$ and under high soil moisture conditions $\left[E_{t}^{S F}=1.66\right.$ $\left.\left(1-\mathrm{e}^{-1.25 \mathrm{Dz}}\right), \mathrm{R}^{2}=0.51\right]$, reaching a stable value of $1.5 \mathrm{~mm} / \mathrm{d}$ at high $D_{z}$, lower than that of southern-edge trees (Fig. 2a). All relationships were significant at $p<0.01$; similarity and dissimilarity of relationships based on location and soil moisture were evaluated based on $p=0.05$.

Trees at southern edges of clumps received more light, transpired more, and were more sensitive to $D_{z}$ and $\theta$. Further investigating these relationships, because the effect of soil moisture on southern edge tree transpiration is likely to be continuous rather than discrete, we related southern $E_{t}^{S F}$ to both $D_{z}$ and $\theta$ as continuous variables $\left[E_{t}^{S F}=3.60\right.$ (1 $\left.\mathrm{e}^{-1.73 D z}\right)+7.11 \theta-1.53, \mathrm{R}^{2}=0.55$; Fig. $\left.2 \mathrm{~b}\right]$. Conditions of high soil moisture and high $D_{z}$ are not common (compare Fig. 1b and d); thus, transpiration was highest and, surprisingly, similar under both high soil moisture combined with moderate $D_{z}$ and under low soil moisture combined with high $D_{z}$ (Fig. 2b).

Energy balance measurements were available for southern edge trees for 119 days (due to technical problems with the IRTS-P sensor); these energy balance estimates of $E_{t}\left(E_{t}^{E B}\right)$ were used as an independent check of $E_{t}^{S F}$ (Fig. 3). Despite some bias, the two independent estimates of $E_{t}$ agree reasonably well $\left(E_{t}^{S F}=0.88 E_{t}^{E B}+0.21, \mathrm{R}^{2}=0.59\right.$, $p<0.001$; root mean square error, RMSE $=0.66 \mathrm{~mm} / \mathrm{d}$ ), with mean $E_{t}^{S F}$ of $2.5 \mathrm{~mm} / \mathrm{d}(\mathrm{SD}=1.0 \mathrm{~mm} / \mathrm{d})$ and mean $E_{t}$ based on the energy balance of $2.6 \mathrm{~mm} / \mathrm{d}(\mathrm{SD}=0.9 \mathrm{~mm} / \mathrm{d})$, suggesting that both methods produce reliable estimates in this setting. The intercept of the relationship between $E_{t}^{S F}$ and $E_{t}^{E B}$, was not significantly different from zero ( $p=0.277)$; forcing the relationship through zero resulted in a slope of 0.95 with similar statistics (red line in Fig. 3).

\subsection{Evapotranspiration at the flux footprint scale}

Sap flux was rescaled to the flux footprint $E_{t, f p}$, where the fraction of tree cover averaged 33\% (SD $=8 \%$ ), showing substantially smaller range than $E T_{E C}$, despite the large range of the available energy $\left(R_{n e t}\right.$; Fig. 4) and $D_{z}$ (Fig. 1). Note that sap flux data were not available at the end of the fall, necessitating estimating tree transpiration based on energy balance measurements. Energy balance-based transpiration was available for the southern-edge trees only. Adjusting these measurements to represent entire clumps, in which trees on average transpire at lower rate than southern-edge trees, was done multiplying by the ratio of transpiration of the average tree in a clump to that in southern-edge trees (0.79; Fig. 2). This ratio (higher than the 0.70 average for the entire period) was invariable owing to persistently high soil moisture and low $D_{z}$ during that period.

The greatest difference between $E_{t, f p}$ and $E T_{E C}$ is seen in spring (Fig. 4), because in spring grass foliage is ample and active (the grass reaches highest leaf area in April - May, Montaldo et al., 2008), re- 


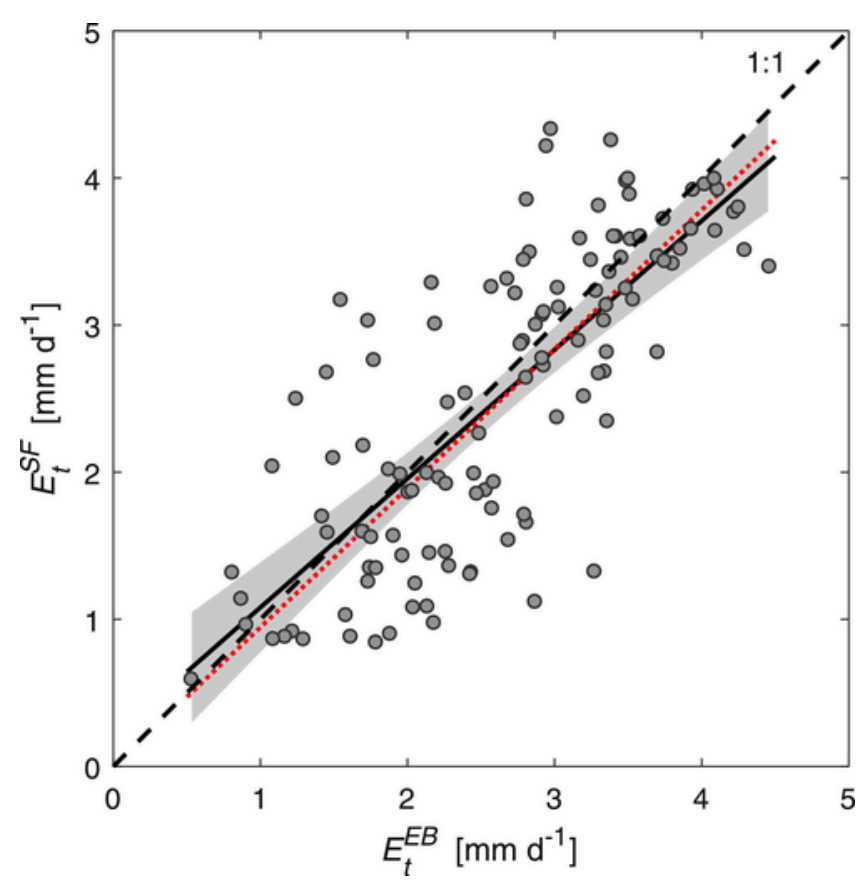

Fig. 3. Comparison of transpiration of southern-edge trees estimated from scaled sap flux $\left(E_{t}^{S F}\right)$ and based on energy balance of the canopy at the southern-edge of a clump $\left(E_{t}^{E B}\right)$. Data are of 119 days. The $95 \%$ confidence interval is shown as a gray band. The intercept was not different from zero, and a regression forced through the intercept had a slope of 0.95 (red dashed line) with similar statistics.

sulting in high $E_{g}$ (Fig. 5). Note that both modeled $E_{g}$ and $E_{b s}$ matched well the available energy balance-based estimates (insets in Fig. 5, $\mathrm{R}^{2}=0.52$ and $\mathrm{RMSE}=0.18 \mathrm{~mm} / \mathrm{d}$ for $E_{g} ; \mathrm{R}^{2}=0.63$ and RMSE $=0.12 \mathrm{~mm} / \mathrm{d}$ for $E_{b s}$ ), suggesting that the simple models are reasonably reliable. Although soil moisture was higher in spring 2016 than that of 2017, $E_{t, f p}$ of 2016 was similar to $E_{t, f p}$ of 2017, but $E T_{E C}$ was higher in 2016 (Fig. 4) due to the contribution of $E_{g}$ (Fig. 5). $E_{t, f p}$ was also lower than $E T_{E C}$ in early summer, 2015 (Fig. 4), consistent with increased soil moisture from late spring and early summer rains (Fig. 1), and thus soil evaporation (Fig. 5). Note that early summer rain in 2015 produced higher soil moisture than in the drier summer of 2017; the latter summer followed a drier spring than the spring of 2016, and, consequently, $E_{b s}$ was higher in the early summer of 2015 (Fig. 5). $E_{w}$ was negligible most of the year, except in fall, when it was often of similar amount ( $\sim 0.2-0.5 \mathrm{~mm} / \mathrm{d}$ ) to the other three ET components (Fig. 5).

The invariability of $E_{t, f p}$ relative to that of $E T_{E C}$ (Fig. 4) manifested in poor relationship between the two fluxes (Fig. 6a; $\mathrm{R}^{2}=0.06$, RMSE $=0.72 \mathrm{~mm} / \mathrm{d} ; p<0.0001$ ), where $E_{t, f p}$ comprised all of $E T_{E C}$ when fluxes are very low, and diminished in relative importance with increasing $E T_{E C}$. As expected $E_{w}$ was also not related to $E T_{E C}$ (Fig. 6a). In contrast, the other $E T$ components, $E_{g, f p}$ and $E_{b s, f p}$ increased with $E T_{E C}\left(E_{g, f p}=0.021 E T_{E C}+0.173 E T_{E C}^{2}, \mathrm{R}^{2}=0.44, \mathrm{RMSE}=0.94 \mathrm{~mm} /\right.$ $\mathrm{d}, \quad$ and $\quad p<0.0001 ; \quad E_{b s, f p}=0.068 \quad \mathrm{e}^{0.896} \quad$ ETEC, $\quad \mathrm{R}^{2}=0.31$, RMSE $=1.07 \mathrm{~mm} / \mathrm{d}$, and $p<0.0001$ ), and their sum, the pasture evapotranspiration, was strongly non-linearly related to $E T_{E C}$ $\left(E_{p}=0.094-0.022 E T_{E C}+0.28 E T_{E C}^{2}, \mathrm{R}^{2}=0.70, \mathrm{RMSE}=0.66 \mathrm{~mm} /\right.$ d; $p<0.0001$; Fig. 6b), becoming the main component of $E T$ at the highest $E T$ values (Fig. 6). Thus, adding the estimates of $E_{p}$ to $E_{t, f p}$ and $E_{w}$, the component sum $E T$ estimate agreed well with $E T_{E C}$ (i.e. it includes the unity line for much of the range; Fig. $6 \mathrm{~d}, \mathrm{R}^{2}=0.71, E_{t, f p}+$ ${ }_{p}+E_{w}=0.89 E T_{E C}+0.17, p<0.0001 ; \mathrm{RMSE}=0.01 \mathrm{~mm} / \mathrm{d}$; forcing the relationship through zero resulted in a slope of 0.99 with similar statistics), reflecting the changing relevance of $E_{b s}$ and $E_{g}$ during periods of changing soil moisture.
The relative contribution of each ET component to ET is shown in Fig. 7, using the fitted lines between progressively added components and $E T\left(E_{w}=0.061 E T_{E C}-0.01, \mathrm{R}^{2}=0.01 ; E_{w}+E_{b s, f p}=0.143\right.$ $E T_{E C}+0.051 \quad E T_{E C}{ }^{2}, \quad \mathrm{R}^{2}=0.22 ; \quad$ and $\quad E_{w}+E_{b s, f p}+E_{g, f p}=0.164$ $\left.E T_{E C}+0.2224 E T_{E C}^{2}, \mathrm{R}^{2}=0.67\right) . E_{w}$ relative contribution to $E T$ was negligible except during the lowest $E T$ conditions (mostly cold periods); the relative contributions of $E_{g, f p}$ and $E_{b s, f p}$ increased with $E T$, while the relative contribution of $E_{t, f p}$ decreased appreciably (Fig. 7).

\section{Discussion}

This study showed that, compared to total evapotranspiration, the transpiration of wild olives was nearly constant over the hydrologic year, insensitive to variation in soil moisture and atmospheric conditions. This is the outcome of compensating trends: as soil moisture decrease and resistance to root water uptake increase, so does the force driving evaporation (Oishi et al., 2008). Thus, in dry periods, when evapotranspiration from the grass cover is dominated by low evaporation from the nearly bare soil, $E_{t}$ dominates ecosystem ET. In contrast, under favorable spring environmental conditions, the pasture leaf area transpires at high rates, dominating the high ET during that season. We demonstrate that proper accounting for heterogeneity of sources within the eddy covariance footprint seems to have overcome potential errors from not preserving an important assumption of the method, the land-surface homogeneity, highlighting the method's reliability in such inhomogeneous ecosystem.

\subsection{Seasonal variations in contributing ET components}

Our estimates of $R_{n e t} E_{t}$ and $E T$ and their seasonal dynamics are consistent with those reported in similar ecosystems (Baldocchi et al., 2004; David et al., 2007; Paco et al., 2009; Raz-Yaseef et al., 2010; Link et al., 2014). As can be seen in the seasonal pattern of water and energy fluxes at the site (Fig. 4), ET broadly tracked $R_{\text {net }}$, but $E_{t}$ seemed far less responsive. Indeed, compared to $E T, E_{t}$ of wild olives is nearly constant (Fig. 6a) and unrelated to ET, as was shown in both broadleaved and deciduous forests (Oishi et al., 2010; Tor-ngern et al., 2017; Ward et al., 2018; Stoy et al., 2019). The relative invariability of transpiration is consistent with the large variation observed in carbon flux exchanges of these wild olives (Montaldo and Oren, 2016). This is because canopy stomatal conductance was very sensitive to variation of vapor pressure deficit, so as the driving force for transpiration increased, conductance compensated and transpiration changed to a negligible extent. However, the variation in conductance translated to predictable variation in carbon flux. This contrasts findings in a Tunisian rainfed olive orchard, in which spring and summer $E_{t}$ (also based on sap flow measurements) was more sensitive to annual precipitation, likely because the very dry climate (annual rain ranged from $116 \mathrm{~mm}$ to $413 \mathrm{~mm}$, averaging $300 \mathrm{~mm}$ over three study years) force these cultivated trees to be very sensitive to variation in soil water availability (Chebbi et al., 2018). In our site, $E_{t}$ is far less than $E T$ in spring, when $67 \%$ of the area is covered by grass at the height of its leaf display and activity (e.g., Montaldo et al., 2008). Under favorable spring radiation, vapor pressure deficit, and soil moisture, the grass leaf area transpires at fast rates, adding vapor to that originating from evaporation of bare soil and intercepted rainfall directly from the soil and tree clumps. Pasture evapotranspiration is strongly related to soil moisture conditions and ET (Fig. 6), and is the principal contributor to ET during periods of high ET (up to $87 \%$, Fig. 7). Conversely, in dry periods, $E_{t}$ of trees dominants the rather low ecosystem ET (up to 78\%, Fig. 7).

These dynamics must be considered in ecohydrological modeling. The two main sources of $E T\left(E_{t}\right.$ and $\left.E_{p}\right)$ differ greatly in their contri- 

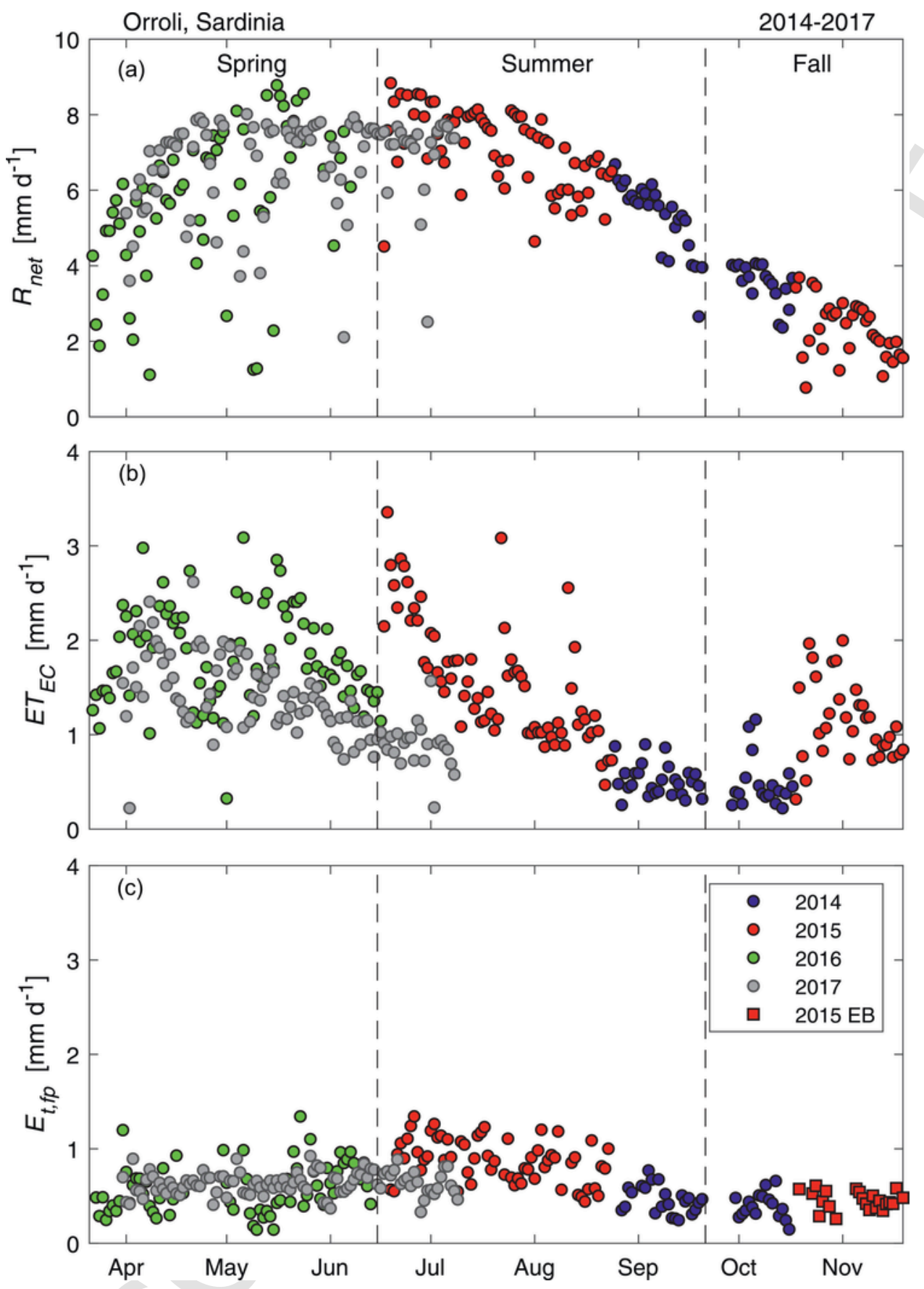

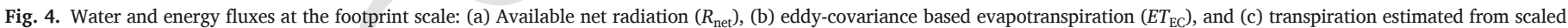
sap flux normalized to the footprint area $\left(E_{\mathrm{t}, \mathrm{fp}}\right)$ ("2015 EB" are the estimates based on the energy balance). The boundaries of the seasons are indicated by vertical dashed lines.

bution (Fig. 7) and responsiveness to changing soil and atmospheric condition. It is possible that the proportion of an area covered by each of such two vegetation components, an evergreen and a seasonal type, represents a balance between incoming radiation and available moisture, the latter reflecting precipitation amounts and distribution, depth of the soil for water storage, and soil and vegetation characteristics. It is also possible that the proportion of the areal cover by these two types changes (in time and space) with the precipitation regime. However, under a given spatial distribution, our results suggest that the fixed component of ET, contributed by tree transpiration, will likely be higher the more of the area is covered by tree crowns. However, the seasonal dynamics of ET will be greater the smaller is the portion of the area covered by tree canopies. Beyond just affecting ET, the impact carries into the seasonality of the energy budget and associated feedbacks on surface temperature and vapor pressure deficit, and through this effect on stomatal conductance, water-use efficiency and carbon uptake (Montaldo and Oren, 2016).

\subsection{Evapotranspiration and its components in heterogeneous systems}

Although wild olives are common in the Mediterranean region (Lumaret and Ouazzani, 2001; Terral et al., 2004), their transpiration, and their sensitivity to soil moisture availability have rarely 

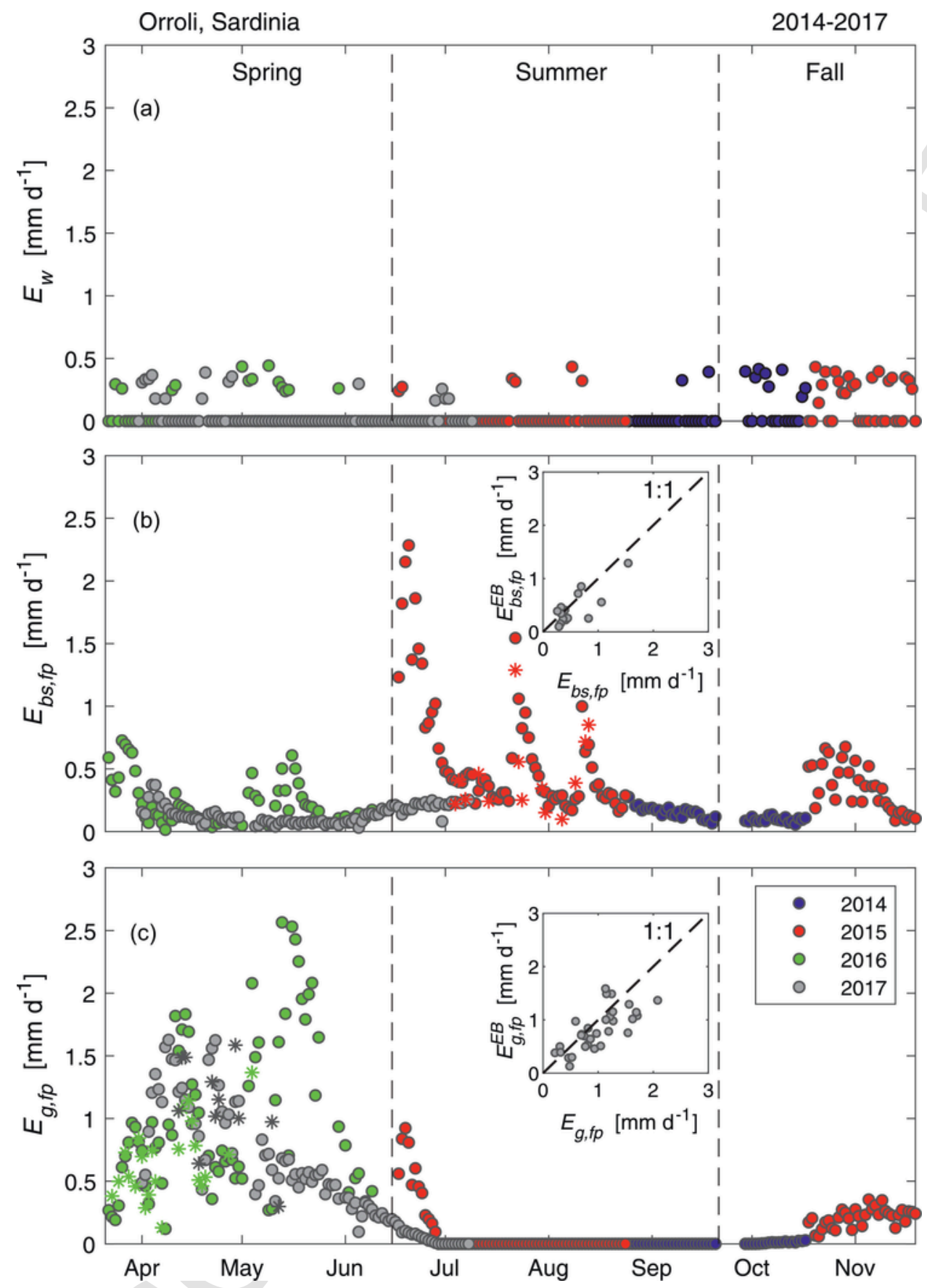

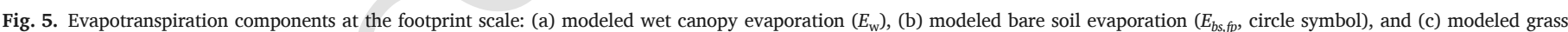

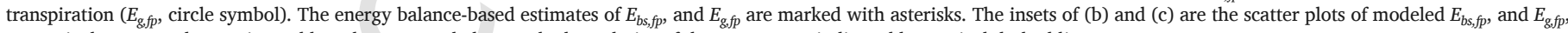
respectively versus values estimated based on energy balance. The boundaries of the seasons are indicated by vertical dashed lines.

been investigated (Lo Gullo and Salleo, 1988; Fernández et al., 1997). Ecosystems dominated by wild olive trees are a patchwork of canopy-tree clumps of different size, randomly distributed and surrounded by herbaceous, mostly grassy vegetation (Breshears, 2006; Villegas et al., 2014). Aiming to scale tree transpiration to ET of the landscape, represented by the eddy-covariance flux footprint, we measured and scaled sap flux, using Granier-type probe (Granier, 1987).

There are three challenges in using this method to estimate stand-scale $E_{t}$. First, the sensor may require specific calibration for the species investigated under particular set of conditions (Steppe et al., 2015). We did not calibrate the sensors for wild olive. Instead, we used the energy balance approach to estimate $E_{t}$ of the canopy at the southern edge of a clump near the eddy-covariance tower, and found it similar to the scaled sap-flux of trees located in that edge (Fig. 3). This lends confidence in the sap-flux scaled $E_{t}$, and provided means for estimating $E_{t}$ in late fall, when the sap flux system failed to provide data due to low output from the solar panels, while the energy balance instruments continue to function. Second, scaling sap-flux measured in a small patch of the xylem to the canopy requires identifying and accounting for systematic sources of variation (Oren et al., 1998). Differences in soil depth near the base of the monitored trees (Table 1) may indicate variation among individuals in access to water, but considering how shallow the soil was in general, and how lit- 

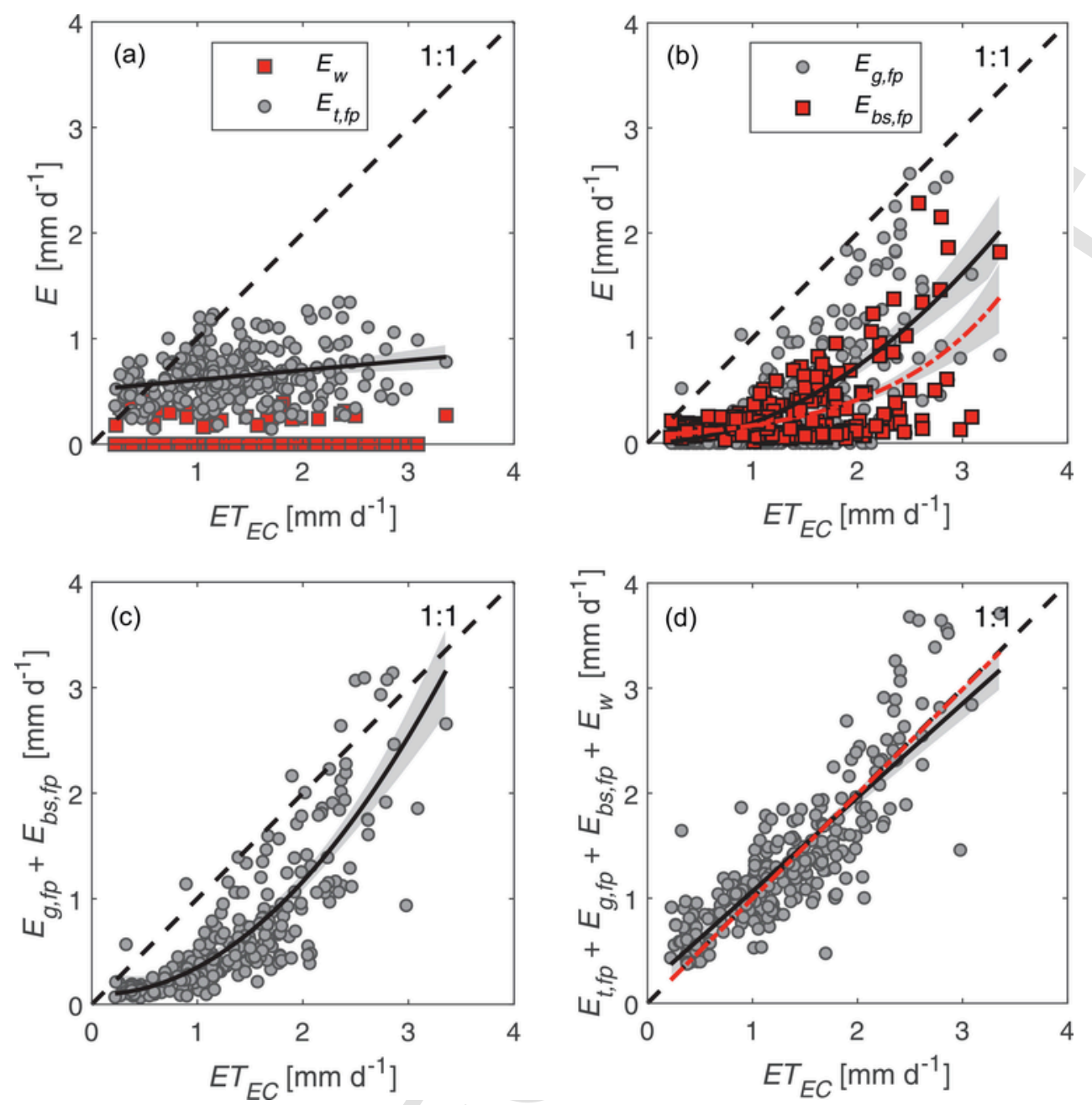

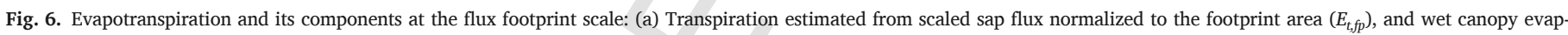

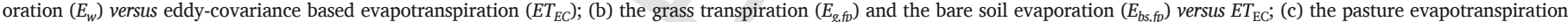

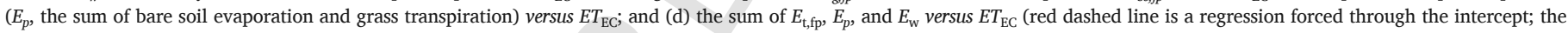
resulting slope is 0.99 ). Fitted lines are in continuous lines and the $95 \%$ confidence interval is shown as a gray band.

tle water can be stored in it relative to the amount transpired, it is not surprising that soil depth did not elicit systematic variation in sap flux. Nevertheless, our results may be independent of soil depth, because water used by trees during the dry season was likely absorbed by roots in the underlying fractured rock (Schwinning, 2010; Rempe and Dietrich, 2018), playing similar role to that of a deeper soil reservoir. The active xylem (sapwood) depth in our monitored trees exceeded the sensor depth only narrowly, thus not requiring accounting for radial trends (Phillips et al., 1996). Tree diameter did not affect sap flux, probably because height differences were not large enough to induce appreciable variation in path-length resistance to water flow (Schäfer et al., 2000). Furthermore, unlike in situation where crowns are separated and experience variation in irradiance along their circumference (Oren et al., 1999), crowns in the dense clumps are small and surrounded by the compact canopy. Thus, despite the range in tree diameter, crowns were not likely to experience azimuthal variation in radiation. Indeed, the only systematic source of variation of sap flux was related to azimuthal position in the clump. Trees located in the southern edge of clumps, thus receiving more light, transpired more and showed greater sensitivity to increasing $D_{z}$ and soil moisture than trees located in the center or northern edge (Fig. 2). Thus, southern-edge trees are situated for greater physiological activity, but require more water to meet their potential performance. We accounted for the variation of sap flux with location in clumps in scaling to $E_{t}$.

The third challenge in scaling sap flux measurements to stand $E_{t}$ is unique to heterogeneous systems (Oishi et al., 2008), especially if part of the landscape, here $\sim 67 \%$, is not covered by tree canopy. We accounted for the aerial cover of wild olive clumps, and scaled the evapotranspiration components, measured or modeled, by the fractional contribution of tree or pasture (grass or bare soil) cover, thus addressing the heterogeneity within the footprint (Detto et al., 2006). We gained further confidence in the $E_{t}$ estimate when, summed with the rest of the evapotranspiration components, the component sum of ET matched reasonably well the value obtained from eddy covariance measurements (Fig. 6d). Indeed, proper accounting for heterogeneity of sources within the eddy covariance footprint (Oishi et al., 2008) seems to have overcome potential errors from not preserving an important assumption of the method (Finnigan, 2004; Belcher et al., 2012; Griebel et al., 2016).

\section{Conclusions}

In a typical heterogeneous Mediterranean ecosystem in Sardinia, we combined eddy-covariance estimates of evapotranspiration (ET) with sap flux and energy balance estimates of wild-olive tree transpiration, a common tree species of the region, and with modeled evap- 


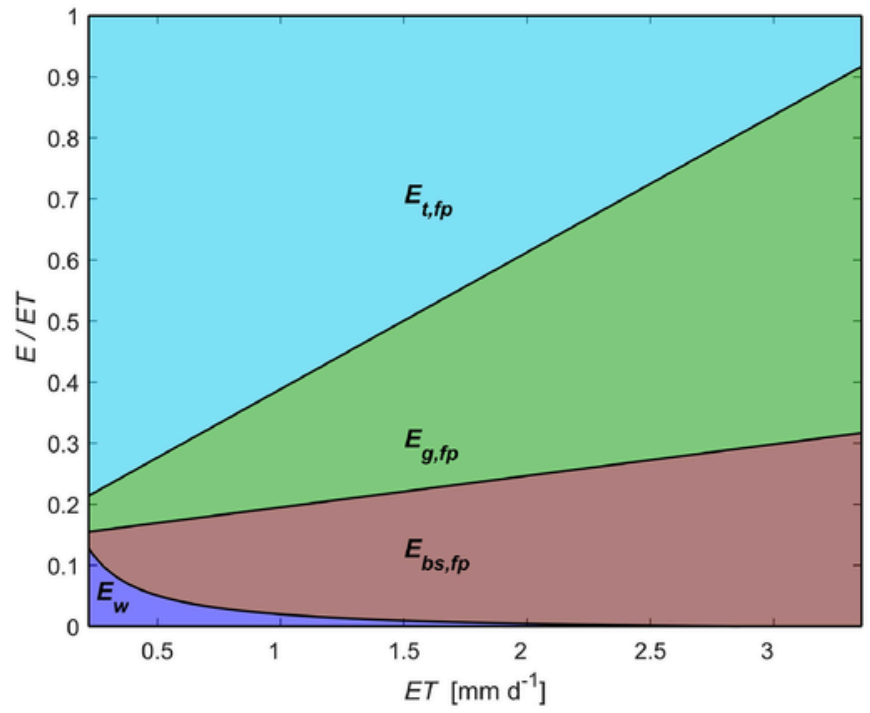

Fig. 7. The relative contribution of the evapotranspiration $(E T)$ components $\left(E_{w}\right.$ : wet canopy evaporation; $E_{b s, f p}$ : bare soil evaporation; $E_{g, f p}$ : grass transpiration; $E_{t, f p}$ : tree transpiration) to $E T$ at the flux footprint scale, estimated using the fitted lines between progressively added evapotranspiration components $\left(E_{w}, E_{w}+E_{b s, f p}\right.$, and $E_{w}+E_{b s, f p}+E_{g, f p}$, and $\left.E_{w}+E_{b s, f p}+E_{g, f p}+E_{t, f t}=E T\right)$ versus ET.

otranspiration from the seasonal grass. Transpiration of the tree clumps in the footprint $\left(E_{t}\right)$, summed up with the modeled evapotranspiration components of the surrounding grass, matched latent heat flux measurements, lending confidence in the estimates. Proper accounting for heterogeneity of sources within the eddy covariance footprint seems to have overcome potential errors from not preserving an important assumption of the method, the land-surface homogeneity, highlighting the methods reliability in such inhomogeneous ecosystem. Compared to ET, $E_{t}$ of wild olives was nearly constant over the hydrologic year, insensitive to variation in soil moisture and atmospheric conditions. Under favorable spring environmental conditions, the pasture area transpires at high rates, contributing to, and dominating the high ET during that season. Conversely, in dry periods, when evapotranspiration from the grass cover is dominated by low evaporation from the, principally, bare soil, $E_{t}$ dominants ecosystem $E T$.

Correct modeling of the two main ET components is crucial not only for proper estimation of the water, energy and carbon exchanges between the atmosphere and biosphere but, by extension, also for water resource management and land use planning, currently and under future climate (Flato et al., 2013; Knapp et al., 2015; Ozturk et al., 2015). This is because, in areas with a pronounced dry season, these heterogeneous ecosystems share limited amounts of water with downstream populations. Indeed, in such regions, land-cover change strategies (i.e., exchanges between tree and grass cover fractions) may affect the seasonality of ET sufficiently to produce tangible changes in water flow to the reservoirs. Such a tool may become essential as changing climate is manifested in the distribution of precipitation (but not the annual amounts), shifting away from the seasons of low ET and high water yield to the seasons of high ET (Flato et al., 2013; Montaldo and Oren, 2018). Under such conditions, a shift from grassy vegetation to tree cover, e.g., to allow a greater carbon sequestration, will increase ET when the grass is inactive during summer (thus cooling down the surface, and perhaps reducing vapor pressure deficit and increasing carbon uptake), but reduce $E T$ in late winter and spring, the seasons most important for harvesting water.

Because transpiration of wild olives was nearly constant during the observed period, including during the dry period, and the soil layer was thin $(\sim 17 \mathrm{~cm})$, tree water requirement must be satisfied by another source of water, presumably the water in the underlying fractured rocks (Schwinning, 2010; Rempe and Dietrich, 2018). Future efforts should investigate the role of water uptake by tree roots penetrating the rocks, its importance during the dry periods, and its impact on the seasonal and annual water balance.

\section{Uncited references}

Brutsaert, 1982

\section{Declaration of Competing Interest}

The authors declare that they have no known competing financial interests or personal relationships that could have appeared to influence the work reported in this paper.

\section{Acknowledgements}

This work was supported by Ministry of Education, University and Research (MIUR) through the SWATCH European project of PRIMA MED program, the ALTOS European project of PRIMA MED, the FLUXMED European project of WATER JPI program, and by FORESTAS Sardinian Agency. Financial support for Ram Oren was provided by the 2015 "Visiting scientist program" of the Università di Cagliari, and by the Erkko Visiting Professor Program of the Jane and Aatos Erkko 375th Anniversary Fund through the University of Helsinki. Finally, we thank the editor Johannes Laubach and two anonymous reviewers for their useful comments and suggestions.

\section{References}

Baldocchi, D., 2003. Assessing the eddy covariance technique for evaluating carbon dioxide exchange rates of ecosystems: past, present and future. Glob. Chang. Biol. 9, 1-14.

Baldocchi, D.D., Xu, L., Kiang, N., 2004. How plant functional-type, weather, seasonal drought, and soil physical properties alter water and energy fluxes of an oak-grass savanna and an annual grassland. Agric. Forest. Meteorol. 123, 13-39.

Baldocchi, D., 2008. Breathing of the terrestrial biosphere: lessons learned from a global network of carbon dioxide flux measurement systems. Aust. J. Bot. 56 (1), 1-26.

Belcher, S.E., Harman, I.N., Finnigan, J.J., 2012. The wind in the willows: flows in forest canopies in complex terrain. In: Davis, S.H., Moin, P. (Eds.), Annual Review of Fluid Mechanics 44, Annual Reviews, Palo Alto, p. 479-+.

Bovard, B.D., Curtis, P.S., Vogel, C.S., Su, H.B., Schmid, H.P., 2005. Environmental controls on sap flow in a northern hardwood forest. Tree Physiol. 25 (1), 31-38.

Breshears, D.D., 2006. The grassland-forest continuum: trends in ecosystem properties for woody plant mosaics?. Front. Ecol. Environ. 4 (2), 96-104.

Breshears, D.D., Myers, O.B., Barnes, F.J., 2009. Horizontal heterogeneity in the frequency of plant-available water with woodland intercanopy-canopy vegetation patch type rivals that occurring vertically by soil depth. Ecohydrology 2 (4), 503-519.

Brutsaert, W., 1982. Evaporation Into the Atmosphere: Theory, History, and Applications. Kluwer Academic Publishers, 299.

Chebbi, W., Boulet, G., Le Dantec, V., Lili Chabaane, Z., Fanise, P., Mougenot, B., Ayari, H., 2018. Analysis of evapotranspiration components of a rainfed olive orchard during three contrasting years in a semi-arid climate. Agric. For. Meteorol. 256, 159-178.

Cienciala, E., Mellander, P.E., Kucera, J., Oplustilova, M., Ottosson-Lofvenius, M., Bishop, K., 2002. The effect of a north-facing forest edge on tree water use in a boreal Scots pine stand. Can. J. For. Res.-Revue Can. De Rech. For. 32 (4), 693-702.

Clearwater, M.J., Meinzer, F.C., Andrade, J.L., Goldstein, G., Holbrook, N.M., 1999. Potential errors in measurement of non uniform sap flow using heat dissipation probes. Tree Physiol. 19 (10), 681-687.

David, T.S., Henriques, M.O., Kurz-Besson, C., Nunes, J., Valente, F., Vaz, M., Pereira, J.S., et al., 2007. Water-use strategies in two co-occurring Mediterranean evergreen oaks: surviving the summer drought. Tree Physiol. 27, 793-803.

Detto, M., Montaldo, N., Albertson, J.D., Mancini, M., Katul, G., 2006. Soil moisture and vegetation controls on evapotranspiration in a heterogeneous Mediterranean ecosystem on Sardinia, Italy. Water Resour. Res. 42 (8), 16.

Detto, M., Katul, G., Mancini, M., Montaldo, N., Albertson, J.D., 2008. Surface heterogeneity and its signature in higher-order scalar similarity relationships. Agric. For. Meteorol. 148 (6-7), 902-916.

Domec, J.C., Sun, G., Noormets, A., Gavazzi, M.J., Treasure, E.A., Cohen, E., Swenson, J.J., McNulty, S.G., King, J.S., 2012. A comparison of three methods to esti- 
mate evapotranspiration in two contrasting loblolly pine plantations: age-related changes in water use and drought sensitivity of evapotranspiration components. For. Sci. 58 (5), 497-512.

Fernández, J.E., Moreno, F., Giron, I.F., Blazquez, O.M., 1997. Stomatal control of water use in olive tree leaves. Plant Soil. 190 (2), 179-192.

Finnigan, J., 2004. The footprint concept in complex terrain. Agric. For. Meteorol. 127 (3-4), 117-129.

Flato, G., Marotzke, J., Abiodun, B., Braconnot, P., Chou, S.C., Collins, W., et al., 2013. Evaluation of climate models. In: Stocker, T.F., et al. (Eds.), Climate Change 2013: The Physical Science Basis. Contribution of Working Group I to the Fifth Assessment Report of the Intergovernmental Panel on Climate Change. Cambridge University Press, Cambridge, United Kingdom New York, NY, pp. 741-866, Chapter 9.

Foken, T., 2008. The energy balance closure problem: an overview. Ecol. Appl. 18 (6), 1351-1367.

Franks, S.W., Beven, K.J., Quinn, P.F., Wright, I.R., 1997. On the sensitivity of soil vegetation atmosphere transfer (SVAT) schemes: equifinality and the problem of robust calibration. Agric. For. Meteorol. 86, 63-75.

Fritschen, L.J., Simpson, J.R., 1989. Surface energy and radiation balance system: general description and improvements. J. Appl.Meteorol. 28, 680-689.

Garratt, J.R., 1992. The Atmospheric Boundary Layer. Cambridge Univ. Press, New York.

Granier, A., 1987. Evaluation of transpiration in a Douglas-Fir stand by means of sap flow measurements. Tree Physiol 3, 309-320.

Griebel, A., Bennett, L.T., Metzen, D., Cleverly, J., Burba, G., Arndt, S.K., 2016. Effects of inhomogeneities within the flux footprint on the interpretation of seasonal, annual, and interannual ecosystem carbon exchange. Agric. For. Meteorol. 221, 50-60.

Herbst, M., Roberts, J.M., Rosier, P.T.W., Taylor, M.E., Gowing, D.J., 2007. Edge effects and forest water use: a field study in a mixed deciduous woodland. For. Ecol. Manage. 250 (3), 176-186.

House, J.I., Archer, S., Breshears, D.D., Scholes, R.J., 2003. Conundrums in mixed woody-herbaceous plant systems. J. Biogeogr. 30 (11), 1763-1777.

Jackson, N.A., Wallace, J.S., 1999. Soil evaporation measurements in an agroforestry system in Kenya. Agric. For. Meteorol. 94, 2013-2215.

Knapp, A.K., Hoover, D.L., Wilcox, K.R., Avolio, M.L., Koerner, S.E., la Pierre, K.J., et al., 2015. Characterizing differences in precipitation regimes of extreme wet and dry years: implications for climate change experiments. Glob. Chang. Biol. 21 (7), 2624-2633. https://doi.org/10.1111/gcb.12888.

Komatsu, H., Shinohara, Y., Kume, T., Tsuruta, K., Otsuki, K., 2016. Does measuring azimuthal variations in sap flux lead to more reliable stand transpiration estimates?. Hydrol. Process. 30 (13), 2129-2137.

Köstner, B., Granier, A., Cermak, J., 1998. Sapflow measurements in forest stands: methods and uncertainties. Ann. Des Sci. For. 55 (1-2), 13-27.

Kurc, S.A., Small, E.E., 2004. Dynamics of evapotranspiration in semiarid grassland and shrubland ecosystems during the summer mon- soon season, central New Mexico. Water Resour. Res. 40, W09305. https://doi.org/10.1029/2004WR003068.

Link, P., Simonin, K., Maness, H., Oshun, J., Dawson, T., Fung, I., 2014. Species differences in the seasonality of evergreen tree transpiration in a Mediterranean climate: analysis of multiyear, half-hourly sap flow observations. Water Resour. Res. 50, 1869-1894. https://doi.org/10.1002/2013WR014023.

Lo Gullo, M.A., Salleo, S., 1988. Different strategies of drought resistance in three Mediterranean sclerophyllous trees growing in the same environmental conditions. New Phytol. 108, 267-276.

Lumaret, R., Ouazzani, N., 2001. Brief communications. Nature 413.

Maselli, F., Chiesi, M., Bindi, M., 2004. Multi-year simulation of Mediterranean forest transpiration by the integration of NOAA-AVHRR and ancillary data. Int. J. Remote Sens. 25 (19), 3929-3941.

Montaldo, N., Toninelli, V., Albertson, J.D., Mancini, M., Troch, P.A., 2003. The effect of background hydrometeorological conditions on the sensitivity of evapotranspiration to model parameters: analysis with measurements from an italian alpine catchment. Hydrol. Earth Syst. Sci. 7 (6), 848-861.

Montaldo, N., Albertson, J.D., Mancini, M., 2007. Dynamic calibration with an ensemble kalman filter based data assimilation approach for root zone moisture predictions. J. Hydrometeorol. 8, 910-921.

Montaldo, N., Albertson, J.D., Mancini, M., 2008. Vegetation dynamics and soil water balance in a water-limited Mediterranean ecosystem on Sardinia, Italy. Hydrol.Earth Syst. Sci. 12, 1257-1271.

Montaldo, N., Corona, R., Albertson, J.D., 2013. On the separate effects of soil and land cover on Mediterranean ecohydrology: two contrasting case studies in Sardinia, Italy. Water Resour. Res. 49, 1123-1136.

Montaldo, N., Oren, R., 2016. The way the wind blows matters to ecosystem water use efficiency. Agric. For. Meteorol. 217, 1-9.

Montaldo, N., Oren, R., 2018. Changing seasonal rainfall distribution with climate directs contrasting impacts at evapotranspiration and water yield in the western Mediterranean region. Earths Future 6 (6), 841-856.

Moon, M., Kim, T., Park, J., Cho, S., Ryu, D., Kim, H.S., 2015. Variation in sap flux density and its effect on stand transpiration estimates of Korean pine stands. J. For. Res. 20 (1), 85-93.

Moore, G.W., Heilman, J.L., 2011. Proposed principles governing how vegetation changes affect transpiration. Ecohydrology 4 (3), 351-358.

Noilhan, J., Planton, S., 1989. A simple parameterization of land surface processes for meteorological models. Mon. Weather Rev. 117, 536-549.

Oishi, A.C., Oren, R., Stoy, P.C., 2008. Estimating components of forest evapotranspiration: a footprint approach for scaling sap flux measurements. Agric. For. Meteorol. 148 (11), 1719-1732.

Oishi, A.C., Oren, R., Novick, K.A., Palmroth, S., Katul, G.G., 2010. Interannual invariability of forest evapotranspiration and its consequence to water flow downstream. Ecosystems 13, 421-436. https://doi.org/10.1007/s10021-010-9328-3.
Oren, R., Hsieh, C.-I., Stoy, P., Albertson, J., McCarthy, H.R., Harrell, P., Katul, G.G., 2006. Estimating the uncertainty in annual net ecosystem carbon exchange: spatial variation in turbulent fluxes and sampling errors in eddy-covariance measurements. Glob. Chang. Biol. 12, 883-896.

Oren, R., Zimmermann, R., Terborgh, J., 1996. Transpiration response of upper Amazonia floodplain and upland trees and forests to drought braking rains. Ecology 77, 968-973.

Oren, R., Phillips, N., Katul, G., Ewers, B.E., Pataki, D.E., 1998. Scaling xylem sap flux and soil water balance and calculating variance: a method for partitioning water flux in forests. Ann.s Des Sci. For. 55 (1-2), 191-216.

Oren, R., Sperry, J.S., Katul, G.G., Pataki, D.E., Ewers, B.E., Phillips, N., Schafer, K.V.R., 1999. Survey and synthesis of intra- and interspecific variation in stomatal sensitivity to vapour pressure deficit. Plant Cell Environ. 22 (12), 1515-1526.

Ozturk, T., Ceber, Z.P., Türkes, M., Kurnaz, M.L., 2015. Projections of climate change in the Mediterranean basin by using downscaled global climate model outputs. Int. J. Climatol. 35, 4276-4292. https://doi.org/10.1002/joc.4285.

Paco, T.A., David, T.S., Henriques, M.O., Pereira, J.S., Valente, F., Banza, J., Pereira, F.L., Pinto, C., David, J.S., 2009. Evapotranspiration from a Mediterranean evergreen oak savannah: the role of trees and pasture. J. Hydrol. 369, 98-106. https://doi.org/10 1016/j.jhydrol.2009.02.011.

Parlange, M.B., Albertson, J.D., Eichinger, W.E., Cahill, A.T., Jackson, T.J., 1999. Evaporation: use of fast response turbulence sensors, raman lidar and passive microwave remote sensing. In: M.B. (Ed.), Vadose Zone Hydrology: Cutting Across Disciplines.

Phillips, H., Oren, R., Zimmermann, R., 1996. Radial patterns of xylem sap flow in non-, diffuse- and ringporous tree species. Plant, Cell Environ. 19, 983-990.

Ramos, A.F., Santos, F.L., 2009. Water use, transpiration, and crop coefficients for olives (cv. Cordovil), grown in orchards in Southern Portugal. Biosyst. Eng. 102 (3), 321-333.

Raz-Yaseef, N., Rotenberg, E., Yakir, D., 2010. Effects of spatial variations in soil evaporation caused by tree shading on water flux partitioning in a semi-arid pine forest. Agric. For. Meteorol. 150 (3), 454-462.

Rempe, D.M., Dietrich, W.E., 2018. Direct observations of rock moisture, a hidden component of the hydrologic cycle. Proc. Natl. Acad. Sci. USA 115 (11), 2664-2669.

Reynolds, J., Kemp, P., Tenhunen, J., 2000. Effects of long-term rainfall variability on evapotranspiration and soil water distribution in the chihuan desert: a modeling analysis. Plant Ecol. 150, 145-159.

Rodriguez-Iturbe, I., 2000. Ecohydrology: a hydrologic perspective of climate-soil-vegetation dynamics. Water Resour. Res. 36 (1), 3-9.

Sankaran, M., Hanan, N.P., Scholes, R.J., Ratnam, J., Augustine, D.J., Cade, B.S., et al., 2005. Determinants of woody cover in African savannas. Nature 438 (7069), 846-849.

Schäfer, K.V.R., Oren, R., Tenhunen, J.D., 2000. The effect of tree height on crown level stomatal conductance. Plant, Cell Environ. 23 (4), 365-375.

Schäfer, K.V.R., Oren, R., Lai, C.T., Katul, G.G., 2002. Hydrologic balance in an intact temperate forest ecosystem under ambient and elevated atmospheric $\mathrm{CO}_{2}$ concentration. Glob. Chang. Biol. 8 (9), 895-911.

Scholes, R.J., Archer, S.R., 1997. Tree-grass interactions in savannas. Annu. Rev. Ecol. Syst. 28, 517-544.

Schwinning, S., 2010. Ecohydrology bearings - Invited Commentary the ecohydrology of roots in rocks. Ecohydrology 3, 238-245.

Steppe, K., Vandegehuchte, M.W., Tognetti, R., Mencuccini, M., 2015. Sap flow as a key trait in the understanding of plant hydraulic functioning. Tree Physiol. 35 (4), 341-345.

Stoy, P.C., et al., 2019. Reviews and syntheses: turning the challenges of partitioning ecosystem evaporation and transpiration into opportunities. Biogeosciences Discuss. https://doi.org/10.5194/bg-2019-85.

Stull, R.B., 1988. An Introduction to Boundary Layer Meteorology. Kluwer Academic Publishers, 666.

Terral, J.F., Badal, E., Heinz, C., Roiron, P., Thiebault, S., Figueiral, I., 2004. A hydraulic conductivity model points to post-Neogene survival of the Mediterranean olive. Ecology 85 (11), 3158-3165.

Tor-ngern, P., Oren, R., Oishi, A.C., Uebelherr, J.M., Palmroth, S., Tarvainen, L., Ottosson-Löfvenius, M., Linder, S., Domec, J.-.C., Näsholm, T., 2017. Ecophysiological variation of transpiration of pine forests: synthesis of new and published results. Ecol. Appl. 27, 118-133. https://doi.org/10.1002/eap.1423.

Villegas, J.C., Espeleta, J.E., Morrison, C.T., Breshears, D.D., Huxman, T.E., 2014. Factoring in canopy cover heterogeneity on evapotranspiration partitioning: beyond big-lea surface homogeneity assumptions. J. Soil Water Conserv. 69 (3), 78A-83A

Ward, E.J., Oren, R., Kim, H.S., Kim, D., Tor-ngern, P., Ewers, B.E., McCarthy, H.R., Oishi, A.C., Pataki, D.E., Palmroth, P., Phillips, N.G., Schäfer, K.V.R., 2018. Evapotranspiration and water yield of a pine-broadleaf forest are not altered by long-term atmospheric $\left[\mathrm{CO}_{2}\right]$ enrichment under native or enhanced soil fertility. Glob. Chang. Biol. 24 4841-4856. https://doi.org/10.1111/gcb.14363.

Williams, D.G., Cable, W., Hultine, K., Hoedjes, J.C.B., Yepez, E.A., Simonneaux, V., et al., 2004. Evapotranspiration components determined by stable isotope, sap flow and eddy covariance techniques. Agric. For. Meteorol. 125 (3-4), 241-258.

Wilson, K.B., Hanson, P.J., Mulholland, P.J., Baldocchi, D.D., Wullschleger, S.D., 2001. A comparison of methods for determining forest evapotranspiration and its components: sap-flow, soil water budget, eddy covariance and catchment water balance. Agric. For. Meteorol. 106 (2), 153-168.

Wright, T.E., Tausz, M., Kasel, S., Volkova, L., Merchant, A., Bennett, L.T., 2012. Edge type affects leaf-level water relations and estimated transpiration of Eucalyptus arenacea. Tree Physiol. 32 (3), 280-293. 